\title{
SHALLOW FAULTS MAPPED WITH SEISMIC REFLECTIONS: LOST RIVER FAULT, DAHO
}

\author{
Mubarik Ali \\ Department of Earth Sciences, Quaid-i-Azam University \\ Richard D. Miller, and Don W. Steeples \\ Kansas Geological Survey, The University of Kansas
}

\begin{abstract}
A high-resolution seismic-reflection survey, cunducted at the intersection of Arentson Gulch road and the westem splay of the Lost River fault scarp in central Idaho, defines a bedrock surface about $80 \mathrm{~m}$ deep which is segmented by several faults forming graben structures. Six meters of total fault displacement can be interpreted on the bedrock reflector while only 1 to $2 \mathrm{~m}$ of displacement can be observed on a shallower refracting interface and the surface fault scarp. This relatively small displacement suggests the westem splay has either been active only recently or extremely infrequently since deposition of the bedrock, or that strike-slip motion may be present. A westward deflection of the major activity along the Lost River fault was probably responsible for the gap in 1983 surface faulting between the Warm Spring and Thousand Springs segments. The inconsistency in total bed displacement based on reflection, refraction, and fault-scarp evidence suggests tectonic activity on the westem splay spans more than just a single episode.
\end{abstract}

\section{Introduction}

Shallow faults considered to be probable future hazards in the Intermountain Seismic Belt are commonly buried beneath unconsolidated sediments. The location and offset of these subsurface shallow faults in many cases can be determined with seismic-reflection surveys.

The seismic survey discussed here was conducted at the intersection of Arentson Gulch road and the Lost River fault scarp (Figure 1). The purpose of the study was to delineate shallow subsurface structure. Arentson Gulch road is subparallel to Doublespring Pass road and about 9 miles to the northwest.

The $36 \mathrm{~km}$ of ground breakage in 1983 along the Lost River fault between Thousand Spring valley and the Lost River range in Idaho has been described as a reactivation of a set of shallow normal faults [Crone and Machette, 1984; Hait and Scott, 1978; Hait, 1985; Crone et al., 1987]. Earthpenetrating radar data collected across the scarp at the Doublespring Pass road suggest that more than just the 1983 faulting event was responsible for fractures and fill material less than $4 \mathrm{~m}$ deep [Bilham, 1985]. The upper $70 \mathrm{~m}$ of the fault zone at Doublespring Pass road was examined with high resolution seismic reflection within a month of the 1983 event [Miller and Steeples, 1986]. The fault zone in the upper $50 \mathrm{~m}$ at Doublespring Pass road is $180 \mathrm{~m}$ wide and predominantly composed of normal faults of varied ages [Treadway et al., 1988].

\section{Geology}

Borah Peak and Dickey Peak are located in the Lost River Range and demonstrate classical basin-range topography in Idaho. The topographic relief of the Lost River Range has

Copyright 1991 by the American Geophysical Union.

Paper number 91GL02161

$0094-8534 / 91 / 91 G L-02161 \$ 03.00$

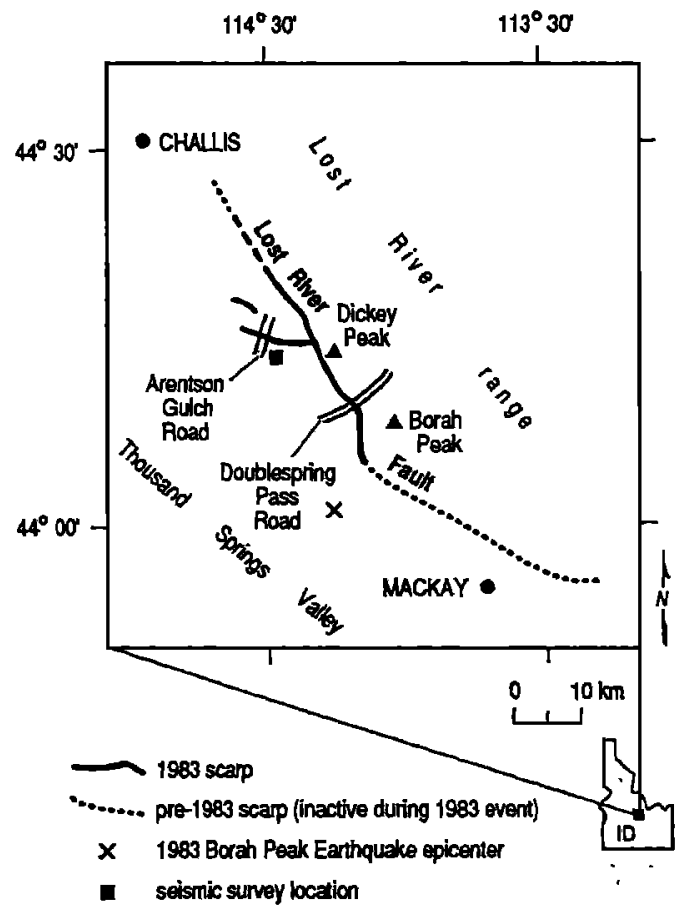

Fig. 1. Study area [modified from Crone et al., 1989].

been described as primarily due to an extended period of normal faulting beginning during middle Miocene and continuing through Holocene [Scott et al., 1985]. Much of the present topographic relief is probably the result of activity during late Pliocene and Pleistocene [Baldwin, 1951]. The Lost River Range is composed of complexly folded and faulted strata ranging in age from Proterozoic to early Pennsylvanian. The Lost River fault, identified as a range front fault, is typical of the Basin and Range structural province north of the Snake River Plain [Baldwin, 1951].

The 1983 earthquake produced $36 \mathrm{~km}$ of northwesttrending surface rupture predominantly along the Lost River fault. Of the $36 \mathrm{~km}, 14.2 \mathrm{~km}$ are found along a west-trending splay diverging from the range front fault at the base of Dickey Peak, extending through the alluvial valley at Arentson Gulch, across a series of bedrock hills, and out into Antelope Flat. The scars at Arentson Gulch and at the crest of the bed ock hills suggest a deeper zone of tectonic movement [Cronc et al., 1985]. The average throw along the west-trending fault splay is less than half a meter. At Arentson Gulch road, however, the scarp possesses as much as $1.6 \mathrm{~m}$ of throw.

\section{Data Acquisition and Processing}

A single 225-m long seismic line with 2-m station spacing was acquired perpendicular to the fault scarp (Table 1). The data were collected along an access road that loosely follows topographic gradient, (i.e., northeast-southwest). The break 
in slope at location 160 marks the fault scarp location (Figure 3).

Table 1. Field Parameters

\section{Source}

Source-receiver geometry

Source-to-nearest-receiver offset

Source-to-farthest-receiver offset

Source interval

Receiver interval

Maximum fold

Geophones per channel .50-caliber rifle

24 meters

70 meters

2 meters

12

$3-40 \mathrm{~Hz}$

(in series)
End-on

2 meters

Data were recorded on a 24-channel, fixed gain, 12-bit digital seismograph (Input/Output DHR-2400). Before digital sampling, the data were high-cut filtered $(-3 \mathrm{~dB}$ at $1000 \mathrm{~Hz}$ with $24 \mathrm{~dB} /$ octave rolloff) anti-alias filtered $(-60 \mathrm{~dB}$ at 2000 $\mathrm{Hz}$ with $60 \mathrm{~dB} /$ octave roll-off $)$, and low-cut filtered, $(-3 \mathrm{~dB}$ at $110 \mathrm{~Hz}$ with $24 \mathrm{~dB} /$ octave roll-off). The 250 -ms records were digitized at a sampling interval of $0.5 \mathrm{~ms}$.

The resolving power of seismic-reflection data depends on the surface station spacing, the recorded reflection frequency spectrum, and the size of the Fresnel zone at the reflector depth. Resolution limit of fault displacement is determined by dominant frequency of the seismic reflection and by seismic velocity. The detection limit and the uncertainty for fault displacement are about $1 / 10$ of a wavelength, which is one meter or less for the data shown here.

Data processing was done on a 32-bit Data General computer at the Kansas Geological Survey. The processing flow was similar to those used on seismic data for petroleum exploration. Differences include more care in pre-reflection and airwave energy muting, detailed NMO velocity analysis, and constraints imposed on statics corrections. Deconvolution of the data was not necessary due to a lack of prominent multiplereflection energy and a low signal-to-noise ratio.

The elevation statics were applied with respect to a sloping datum generally parallel to the ground surface. The sloping datum was used to reduce the magnitude of the corrections, therefore reducing inherent error [Treadway et al., 1988]. Subtle horizontal shifts in shallow subsurface points as a function of depth (remnants of sloping datum corrections) are negligible on this survey.

\section{Interpretation}

Two complementary interpretations are presented here, one based on reflection information and the other on refraction information from the same seismic data set. The reflectionderived information is from depths of 50 to $90 \mathrm{~m}$.

Reflection. Reflected energy at frequencies in excess of $100 \mathrm{~Hz}$ can be observed at $140 \mathrm{~ms}$ on unprocessed field files (Figure 2). The amplitude of ground-roll energy on some files is sufficiently high that it is difficult to confidently identify reflection energy. The general character of reflected energy across the line varies due to relative changes in noise levels, differences in physical characteristics of surficial material, and variations in source-and-receiver ground coupling.

A relatively coherent reflection event can be interpreted on the stacked data between 130 and $140 \mathrm{~ms}$ (Figure 3). This reflection is probably from the Paleozoic carbonate bedrock. Breaks in coherency can be observed in the reflection event between stations 170 and 195, 133 and 155 , and 96 and 105 . Reflection wavelet characteristics vary considerably between stations 185 to 195 and between 132 and 155 .

Wavelet variability observed in the reflection event can be caused by changes in velocity (corresponding to lateral change in lithology), wide-angle reflections, uncompensated static correction, and/or extreme changes in the orientation of the

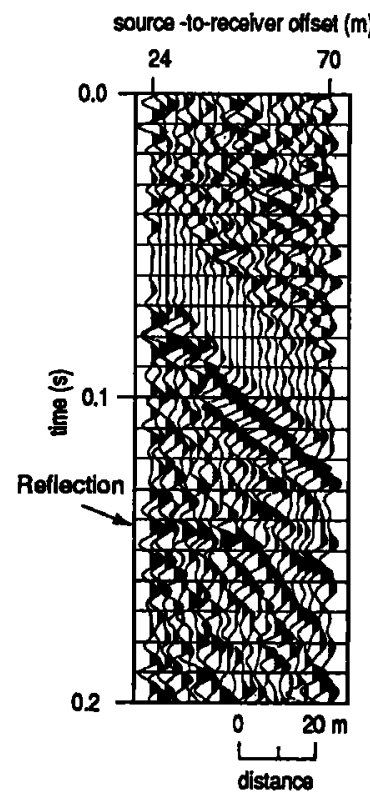

Fig. 2. The filtered field file shows a reflection at $140 \mathrm{~ms}$.
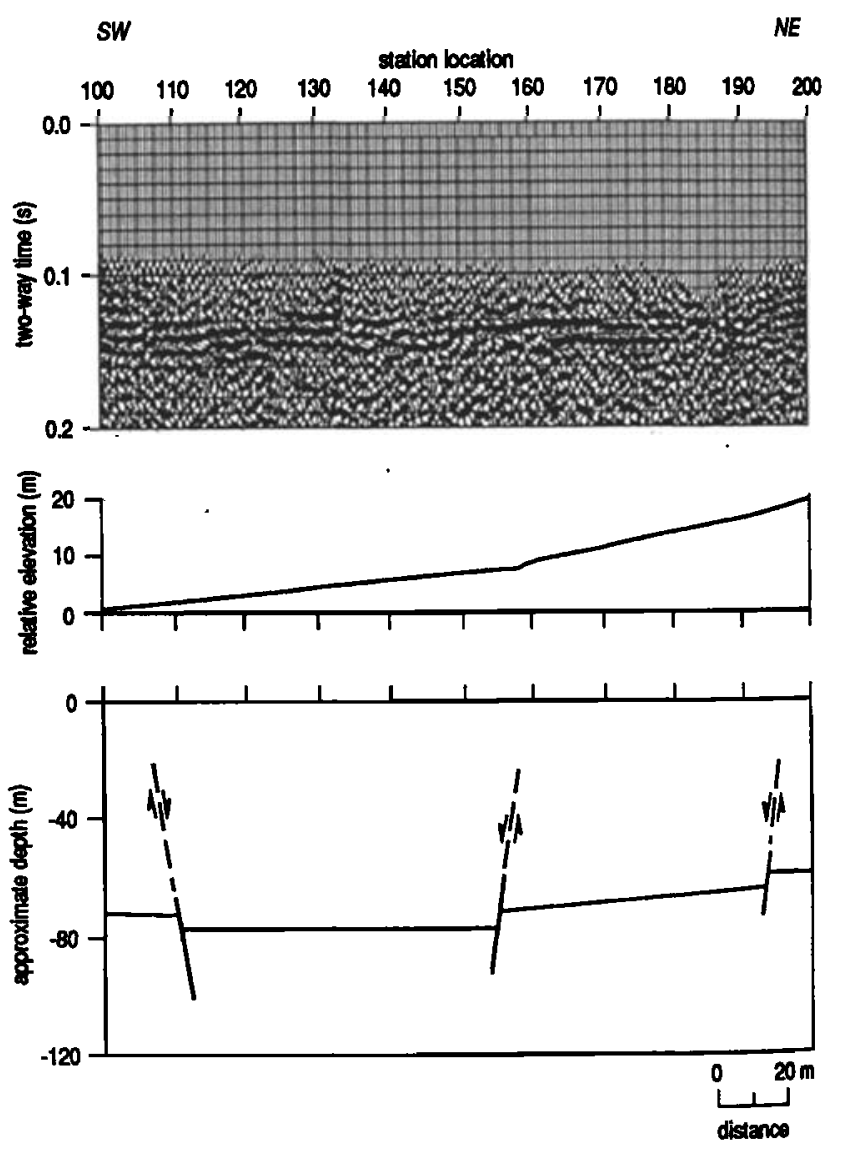

Fig. 3. A reflection at $130 \mathrm{~ms}$ can be observed across most of the 12 -fold CDP stacked section.

reflector [Pullan and Hunter, 1985]. The relative influence of these factors cannot be established with existing data in this tectonically active area. It is likely, however, that all of them contribute to the wavelet variability. Effects of the variable near-surface have been reduced through careful muting, editing, and velocity/static corrections. 
Stacking velocities are relatively consistent (approximately $1200 \mathrm{~m} / \mathrm{s}$ ) from station 115 to 201 . The velocity decreases at station 115 to $1050 \mathrm{~m} / \mathrm{s}$, increasing gradually to $1100 \mathrm{~m} / \mathrm{s}$ on the southwestern end of the line. The drop in velocity is probably related to either a change in lithology or tectonically altered physical properties of the material.

Refraction. Near-surface variations that show up as changes in refracted energy can sometimes be suggestive of shallow structural features. Unique depth determinations derived from refraction energy are not possible on CDP data collected using an end-on source/receiver configuration because the profile is not shot in both directions. Refracted seismic energy arrivals from unreversed profiles on this survey were used, however, to roughly locate distinct and/or rapid changes in subsurface properties within the upper $10 \mathrm{~m}$ (Figure 4)

The CDP data were sorted into a common-offset refraction section to portray variations in the shallow refracting interface (Figure 5). The geophone $46 \mathrm{~m}$ from the source received refractions $(800 \mathrm{~m} / \mathrm{s})$ as first arrivals, therefore possessing the potential of detecting discontinuities in a near-surface layer shallower than $10 \mathrm{~m}$.

The common offset refraction section suggests apparent arrival-time variations between stations 113 and 195 . Assuming horizontally constant $V_{0}$ and $V_{1}$, the depth of the near-surface interface can be determined using a simple equation:

$$
Z_{l}=t i \frac{V_{0} V_{1}}{2 \sqrt{V_{1}^{2}-V_{0}^{2}}}
$$

where $t i=T i-\mathrm{X} / \mathrm{V} 1$ and $T i$ is the intercept time for the refracted waves.

For the cormmon offset section displayed, $X=46 \mathrm{~m}$ (constant), $V_{0}=500 \mathrm{~m} / \mathrm{s}$, and $V_{1}=800 \mathrm{~m} / \mathrm{s}$ are also assumed constant. Thus, $\mathrm{X} / \mathrm{V}_{1}$ and

$$
V_{0} V_{1} / 2 \sqrt{V_{1}^{2}-V_{0}^{2}}
$$

being invariants simplify the depth determination for this section.

Visible disruption in the refracted signal between locations 160 and 163 are probably related to the surface fault scarp produced by the Idaho earthquake of 1983 (Figure 5). The

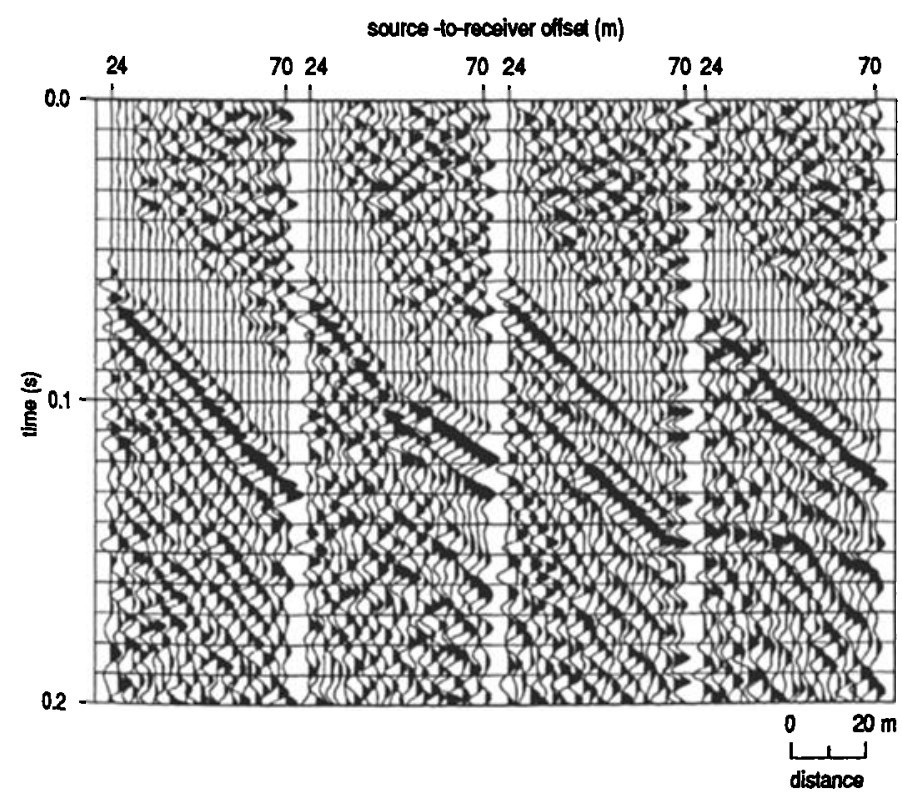

Fig. 4. Filtered data displaying variability in recorded arrivals.
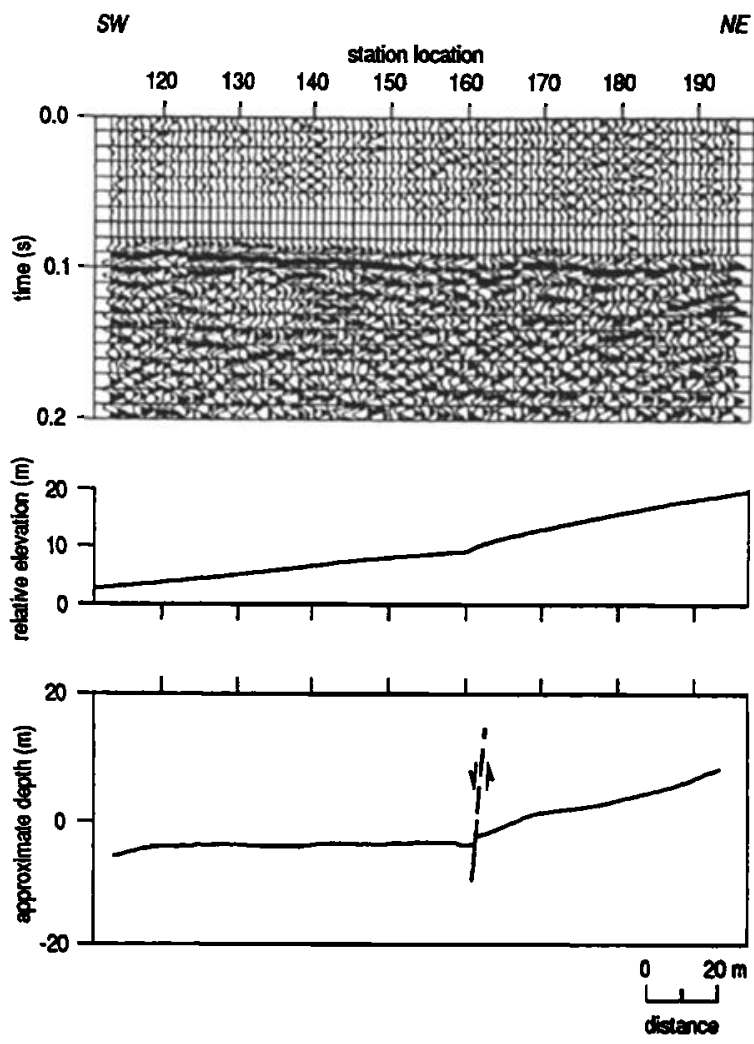

Fig. 5. Disruption in refracted arrivals at locations 161 to 163 on this 46-m common offset section relates with the 1983 earthquake fault scarp.

fault zone at the depth of refractor is interpreted to be $6 \mathrm{~m}$ wide. The refraction interpretation (Figure 5) suggests the near-surface interface is 7 to $10 \mathrm{~m}$ deep and slopes towards the southwest approximately following the ground surface. In tectonically active areas, disruptions in the continuity of the seismic signal are generally considered to be the result from structural variability. Other possible reasons for the calculated depth variations of this first refracting interface includes lithologic changes in refracting media and changes in the acoustic properties of material between the surface and the interface. Correlating the interpreted fault on the refractor and the scarp suggest normal faulting with a southwest dip.

\section{Results and Discussion}

The $130 \mathrm{~ms}$ reflection possesses a southwest dip roughly mimicking the surface topography. Reflector depth across the line varies from approximately 74 to $86 \mathrm{~m}$. Reflections disjointed by faulting achieve good correlation and continuity when compensated for offset by physically cutting the CDP stacked section along interpreted faults and sliding along the cuts until reflection wavelets correlate. This observation lends confidence to the interpretation that the reflector has been segmented by faulting and allows a consistent interpretation across the entire line.

Subtle similarities can be observed between interpreted subsurface structure and the surface topography (Figure 3). It is important to note that these similarities are not related to static problems. With the source-receiver offsets used, both the source static and the receiver static are caused by nearsurface anomalies that are located at least 12 meters horizontally away from the topographic and subsurface structural anomalies.

Interpreted subsurface faults on Figure 3 with potential subdued expression at the ground surface are probably from previous earthquake activity. Years of erosion and deposition 
removed the majority of the surface expression of these seismically identified subsurface geologic features.

Horst-graben-type structures have been interpreted on seismic data near the Lost River fault at Doublespring Pass road [Treadway et al., 1988]. Notable changes in reflection character observed between stations 132-155 and stations 186 195. These chaotic zones within graben-like structures are probably the result of tectonically altered material lacking sufficient acoustic contrast and bed competency to generate coherent seismic reflections. Reflection times suggest bedrock at Arentson Gulch (approximately $80 \mathrm{~m}$ ) is 2 to 3 times deeper than along the Lost River fault at Doublespring Pass road.

Previous studies [Crone and Machette, 1984] in conjunction with our seismic refraction and reflection data suggest the surface fault is probably related to the group of faults interpreted between stations 132 and 160 . Total bedrock displacement interpreted along this seismic survey line is approximately $6 \mathrm{~m}$, representing 4 to 6 times more displacement than is observed on either the common offset refraction section or at the surface. This discrepancy is probably indicative of tectonic activity along the western splay after the top of bedrock was deposited but before the 7-10 m deep refractor was present.

Comparing the $6 \mathrm{~m}$ of displacement on the western splay with the thousands of meters of displacement that has occurred along the frontal fault since Oligocene/Miocene time, it becomes apparent that activity on the western splay is either extremely rare or was initiated during Quaternary. Another possibility is that strike-slip motion may locally accommodate some of the strain resulting in small net dip-slip.

\section{Conclusions}

(1) Segmentation of the approximately 80 -m deep bedrock by several faults with total displacement of approximately $6 \mathrm{~m}$ suggests several episodes of tectonic activity in this area, assuming the 1983 earthquake is characteristic for the area.

(2) Normal faulting seems to have produced graben structures on the surface of the bedrock.

(3) The fault scarp appears to be related to a fault zone interpreted on the seismic data between CDPs 265 and 320 .

(4) Activity on the western splay is either much younger or extremely infrequent with respect to the frontal fault (Lost River fault), or strike-slip motion may be dominant on the western splay.

(5) Based on small total displacement of bedrock, activity on the westem splay is probably secondary rupturing or deflection of major activity along the frontal faultused in conjunction with reflection and surface information.

Acknowledgments. The authors extend gratitude to the Kansas Geological Survey for generously providing the research and computer facilities for the first author. We appreciate the assistance and advice of Tony Crone of the USGS in suggesting this study. Since this study is an outgrowth of the Fulbright program, the first author is thankful to the Center of International Exchange of Scholars (CIES), Washington, D. C., for financial and moral support. Special thanks to Esther Price for manuscript preparation and Pat Acker for quality graphics.
References

Baldwin, E. W., Faulting in the Lost River Range area of Idaho, American Journal of Science, 249, 884-902, 1951.

Bilham, R., Subsurface radar imagery of the near-surface fractures associated with the Borah Peak earthquake, Idaho, Workshop XXVIII on the Borah Peak, Idaho, earthquake, vol. A, U.S. Geological Survey Open-file Report 85-290, 182-194, 1985.

Crone, A. J., and M. N. Machette, Surface faulting accompanying the Borah Peak earthquake, central Idaho, Geology, 12, 664-667, 1984.

Crone, A. J., M. N. Machette, M. G. Bonilla, J. J. Leinkaemper, K. L. Pierce, W. E. Scott, and R. C. Bucknam, Characteristics of surface faulting accompanying Borah Peak Earthquake, central Idaho, Workshop XXVIII on the Borah Peak, Idaho, earthquake, vol. A., U.S. Geological Survey Open-file Report 85-290, 43-58, 1985.

Crone, A. J., M. N. Machette, M. G. Bonilla, J. J. Lienkaemper, K. L., Pierce, W. E. Scott, and R. C. Bucknam, Surface faulting accompanying the Borah Peak earthquake and segmentation of the Lost River fault, central Idaho, Seismological Society of America Bulletin 77, 739-770, 1987.

Hait, M. H., Jr., Doublespring Pass road trench, fault scarps, landslides, and other features associated with the Borah Peak earthquake of Oct. 28, 1983, central Idaho: A Fieldtrip Guide, U.S. Geological Survey Open-file Report 85 290, B, 11-17, 1985.

Hait, M. H., Jr., and W. E. Scott, Holocene faulting, Lost River Range, Idaho, Geological Society of America Abstract with Programs, 10, 217, 1978.

Miller, R. D., D. W. Steeples, Shallow structure from a seismic-reflection profile across the Borah Peak, Idaho, fault scarp, Geophysical Research Letters, 13, 953-956, 1986.

Pullan, S. E., and J. A. Hunter, Seismic model studies of the overburden-bedrock reflection, Geophysics, 50, 1684$1688,1985$.

Scott, W. E., K. L. Pierce, and M. H. Hait, Jr., Quaternary tectonic setting of the 1983 Borah Peak earthquake, central Idaho, Seismological Society of America Bulletin 75, 1053-1066, 1985.

Treadway, J. A., D. W. Steeples, and R. D. Miller, Shallow seismic study of a fault scarp near Borah Peak, Idaho, Journal of Geophysical Research, 93(B6), 6325-6337, 1988.

\footnotetext{
Mubarik Ali, Quaid-i-Azam University, Islamabad, Pakistan

Richard D. Miller and Don W. Steeples, Kansas

Geological Survey, University of Kansas, Lawrence, KS 66047
}

Received: December 3, 1990

Revised: April 11, 1991

Accepted: April 29, 1991 